\title{
ALTERAÇÕES CEREBELARES EM PACIENTES COM CARDIOPATIA CRÔNICA CHAGÁSICA
}

\author{
Alexandre Alencar *
}

Em trabalhos anteriores 1,2,3 chamamos a atenção para alteraçōes do córtex cerebral observadas em pacientes chagásicos crônicos, conseqüentes à hipoxemia do sistema nervoso central resultante do comprometimento cardíaco. A hipoxemia prolongada do tecido nervoso leva a alteraçōes profundas do metabolismo celular, traduzidas, morfologicamente, por aumento do pigmento lipofucsínico encontrado nas células nervosas, por alterações das bainhas de mielina das fibras nervosas e por proliferação da astroglia, além da mobilização microgial. Em pacientes chagásicos crônicos, falecidos em fase de insuficiência cardíaca congestiva, encontramos enorme sobrecarga pigmentar, não sỏmente nas células nervosas mas também nos elementos astrogliais satélites perineuronais. Muitas células nervosas apareciam em estado de "contração celular", hipercromáticas e outras em desintegração. O pigmento resultante da desagregação celular era fagocitado pela microglia, mobilizada e concentrada nos espaços perivasculares. As fibras nervosas finas e delicadas da camada externa de Baillarger se apresentavam degeneradas. Na substância branca, a astroglia havia entrado em proliferação, sob a forma de gliose anisomórfica difusa. Em casos extremos, estas alteraçōes corticais difusas traduziam-se, macroscòpicamente, por atrofia das circunvoluções cerebrais mais ou menos pronunciada.

Continuando esta linha de pesquisa estendemos nossas observações ao córtex cerebelar, o que constitui motivo do presente trabalho.

\section{MATERIAL E METODOS}

Utilizamos os cerebelos de 12 pacientes cardiopatas chagásicos crônicos, todos falecidos em fase de insuficiência cardiaca congestiva. A idade dos pacientes variava em tôrno de 30 anos. Os cerebelos, em sua maior parte, já tínham sido clivados em estudos anteriores, constituindo material de reserva arquivado na Divisāo de Patologia do Instituto Oswaldo Cruz. o material encontrava-se em excelentes condições de fixaçāo, permitindo estudo histológico minucioso. Utilizamos também os cerebelos de 9 pacientes com cardiopatias de etiologias diversas, todos

Trabalho da Secção de Anatomia Patológica do Instituto Oswaldo Cruz e da Divisão de Neuropatologia do Instituto de Neurologia da Universidade Federal do Rio de Janeiro, apresentado ao VI Congresso Brasileiro de Patologia (Salvador, Bahia - 5 a 9 de julho, 1966) e à III Reuniāo da Academia Brasileira de Neurologia (Rio de Janeiro, GB - 24 a 28 de Julho, 1966): * Chefe da Seccão de Anatomia Patológica. 
falecidos em fase de insuficiência cardiaca congestiva. Para comparação, estudamos dois cerebelos de individuos jovens, falecidos acidentalmente.

Como métodos de coloração utilizamos a hematoxilina-eosina, o tricrómico de Gomorí, o cresil-violeta (substancia de Nissl), o de Heidenhain-Woelke (bainhas de mielina em cortes de parafina) e o do carbonato de prata de Rio Ortega em suas variantes. De grande importância foi a coloração pelo Sudan B, para evidenciar lipofucsina e produtos complexos da degradação mielinica insolúveis em álcool e xilol, feita de acôrdo com a seguinte técnica: os cortes eram desparafinados, levados até a água destilada e imersos em solução filtrada de Sudan B durante 5

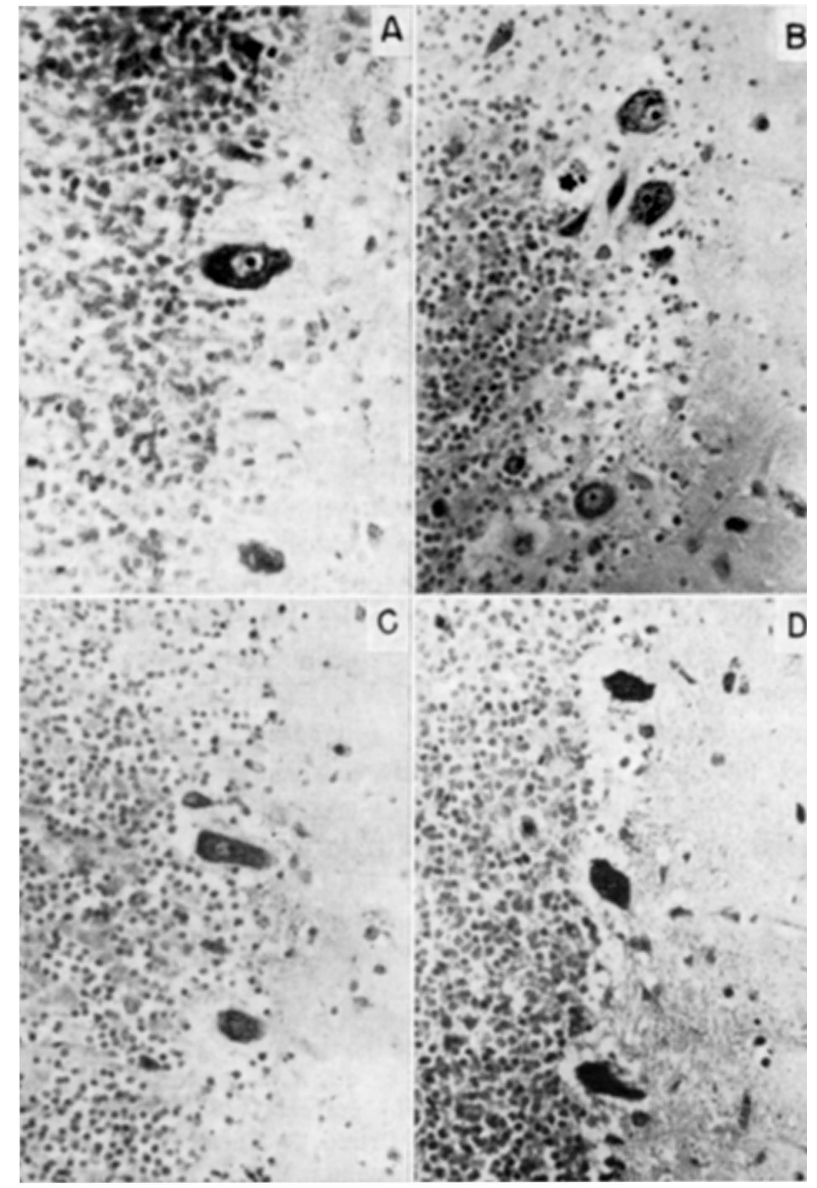

Fig. 1 - Alterações cerebelares em pacientes com cardiopatia chagásica crônica. Aspectos da camada de células de Purkinje, notando-se falhas destas células. As restantes se apresentam alteradas: fragmentação da substância de Nissl $(A, B)$, núcleo excêntrico $(B)$, diminuição de volume celular $e$ núcleo excêntrico $(C)$, hipercromatismo, "contração celular" (D). (Col. cresil-violeta; oc. $7 \times$ - obj. $20 \times$, Olympus). 
minutos (solução saturada de Sudan B em álcool etillico); após lavagem em água destilada os cortes eram montados, sem desidratar, em goma arábica, montagem esta que permite boa transparência dos cortes e conservação durante alguns meses.

\section{RESULTADOS E DISCUSSĀO}

O exame macroscópico dos cerebelos dos pacientes com moléstia de Chagas, nos casos em que foi possivel fazê-lo, não mostrou alterações macroscópicas grosseiras, percebendo-se apenas ligeiro espessamento das lepto-

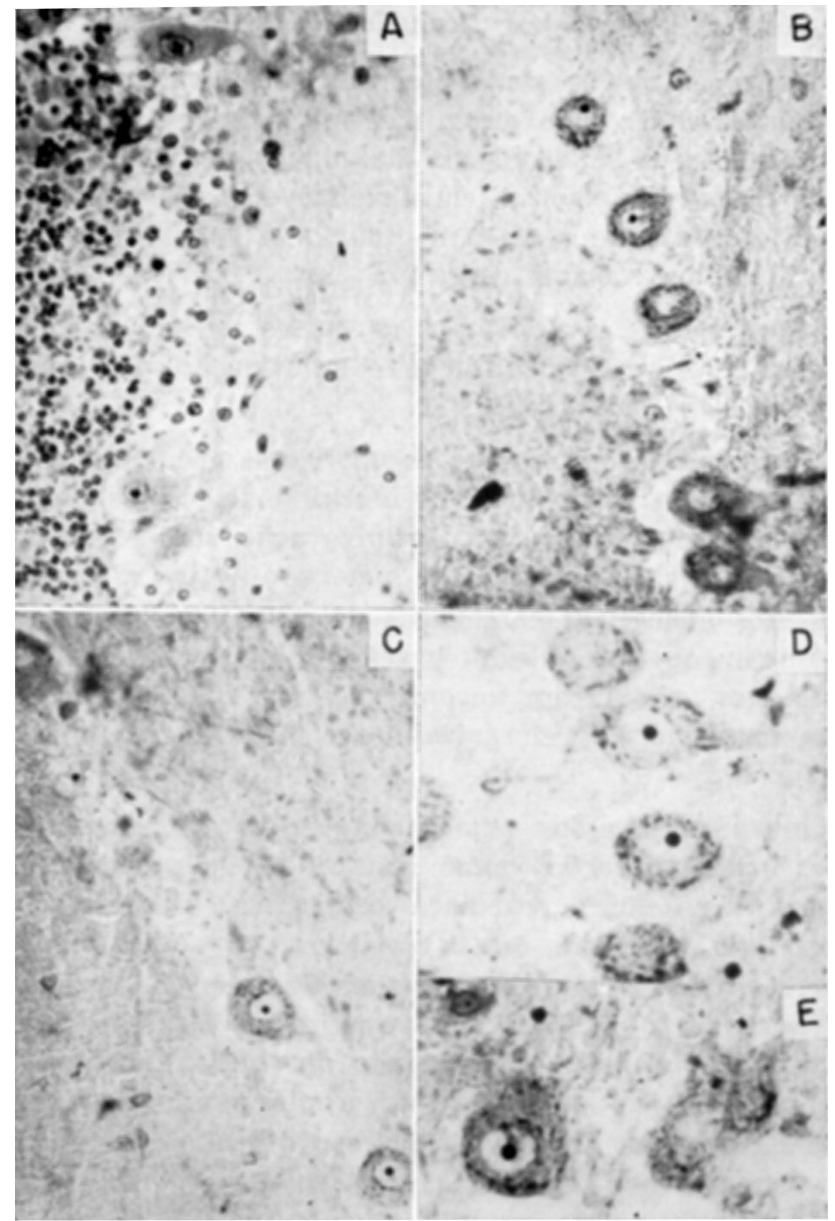

Fig. 2 - Camada de células de Purkinje no cerebelo de individuo normal (óbito por acidente) para comparação com a figura anterior. Notam-se algumas falhas de células $(A, B, C)$, porém as restantes são normais $(D, E)$. (Col. H.E. (A) e cresil-violeta (B, C, D, E,); oc. $10 \times-$ ob. $24 \times(A, B, C) e$ oc. $\times$ - obj. $45 \times(D, E)$ Leitz). 
meninges. Apenas em um dos casos foi possivel verificar diminuição de volume do órgão e irregularidades em sua superfície externa.

Microscòpicamente verificou-se redução numérica na camada das células de Purkinje. Todavia, como mesmo em indivíduos normais esta camada de células não é contínua, foi feita verificação numérica exata: em cada caso contamos, em 5 fólios cerebelares diversos, o número destas células (cortes de 5 micra; obj. $10 \times$ - oc. $5 \times$ ), tirando a média aritmética. Da mesma forma procedemos nos cerebelos "normais". Nos chagásicos obtivemos a média de 18 células por fólio cerebelar, enquanto que nos normais obtínhamos cêrca de 24 células. Esta redução numérica das células de Purkinje já fôra assinalada por Brandão ${ }^{4}$, em 1964.

Os elementos neuronais remanescentes mostravam-se normais ou alterados em graus diversos, indo desde a fragmentação da substância de Nissl até a excentricidade do núcleo, com diminuição do volume celular e hipercromatismo ("contração celular" de Spielmeyer). Na figura 1 podem ser vistas estas alterações que ressaltam quando se compara com o que foi encontrado em individuo normal (fig. 2).

Nas fibras nervosas que formam as cestas peripurkinjeanas, a impregnação argêntica revelou fragmentação e aglutinação conseqüente, talvez, à diminuição do volume celular (fig. 3).

As mais importantes alterações foram vistas mediante a coloração pelo Sudan B. Na camada das células de Purkinje as cestas pericelulares mostraram as bainhas de mielina em desintegração sob a forma de gotículas dispersas pelos interstícios do tecido nervoso ou em disposição catenular. Muitos histiócitos apareciam carregados de gotículas lipídicas (figs. 4 e 5 ). Devemos assinalar que esta desintegração mielínica, bem como a mobilização dos histiócitos, não foram encontradas nos contrôles normais. Os histiócitos eram observados, preferencialmente, concentrados nos espaços perivasculares (fig. 5).

Como jamais verificamos sinais histológicos de processo inflamatório, interpretamos estas alterações como resultantes do processo hipoxêmico determinado pela insuficiência cardiaca congestiva. Com esta idéia realizamos o mesmo tipo de estudo em 9 cerebelos de pacientes com cardiopatias não chagásicas, faleciđos também em fase de falência cardíaca. As alterações encontradas foram idênticas às verificadas nos casos dos chagásicos. Devemos assinalar que êstes últimos não apresentavam sinal algum de arteriosclerose cerebral, de pneumopatias crônicas associadas, nem tampouco alterações hematológicas graves, a não ser discreta anemia ferropriva (os pacientes provinham todos da zona rural).

Acreditamos que a diminuição do fluxo circulatório com a conseqüente hipoxemia do sistema nervoso central, a longo prazo, leve a distúrbios celulares graves, que se traduzem, morfologicamente, pelas alterações encontradas. As conseqüências de ordem clínica e eletrencefalográfica dêstes achados ainda precisam ser determinadas, não sỏmente nos pacientes chagásicos como também em pacientes com outras cardiopatias. 


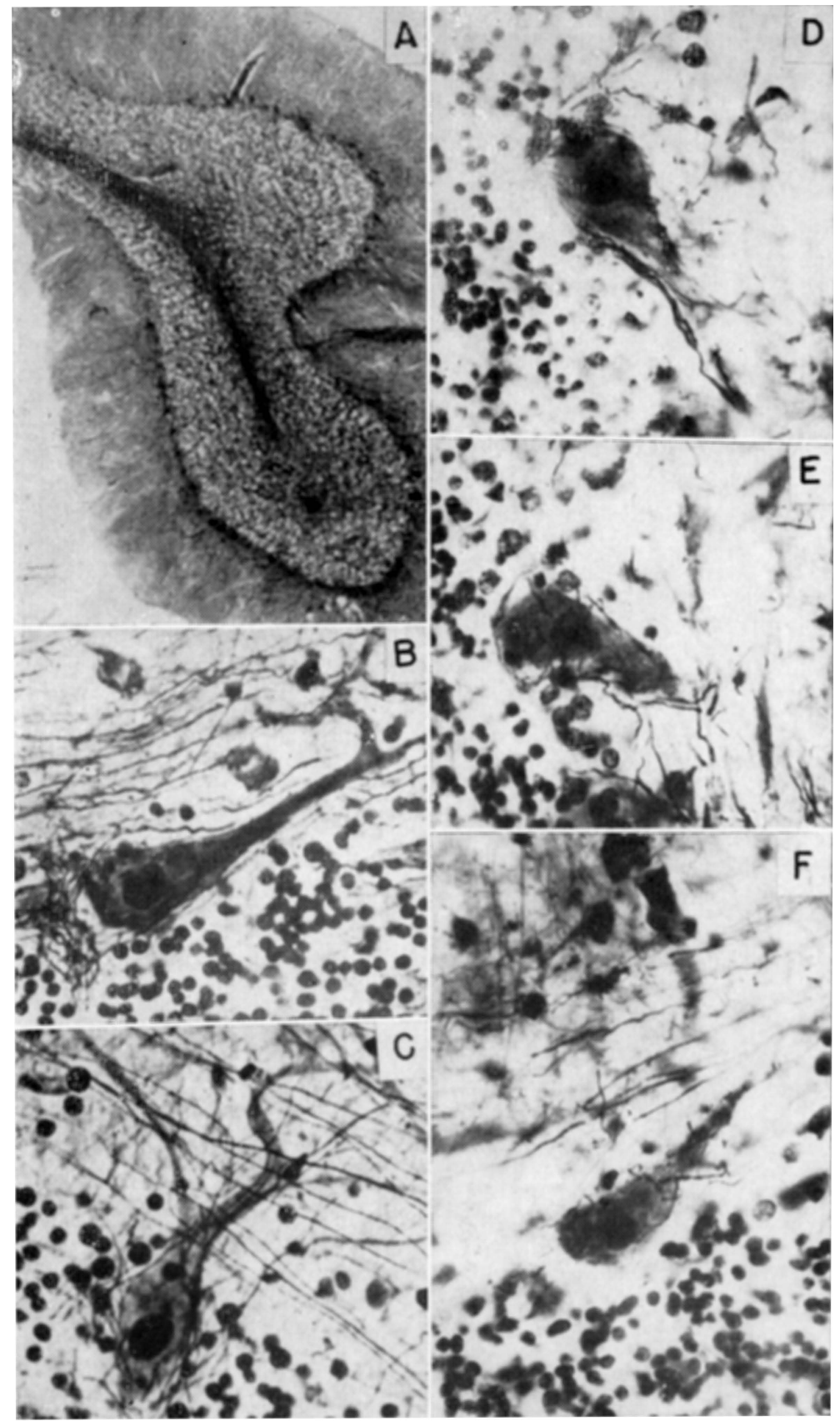

Fig. $3-E m A$, fólio cerebelar normal. Em $B$ e $C$, células de Purkinje normais, com as cestas bem evidentes. $E m D, E$ e $F$, alterações encontradas nestas cestas em casos de cardiopatia crônica chagásica. Cortes em congelação com 25 micra de espessura; impregnação pelo método do carbonato de prata de Rio Hortega; oc. $10 \times-o b j .3,5 \times(A)$; oc. $10-o b j .45 \times(B, C, D, E, F)$, Leitz. 


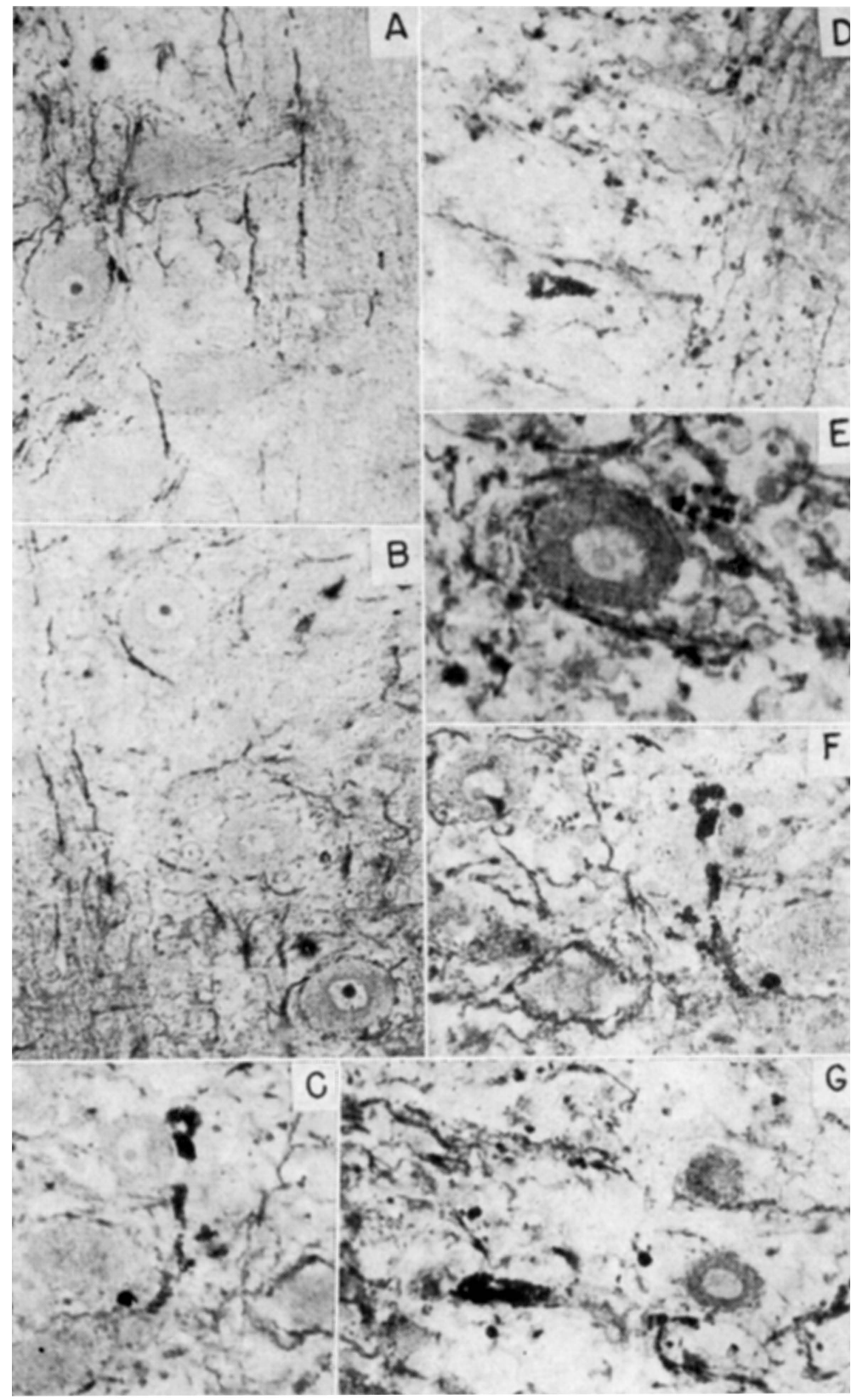

Fig. $4-E m A$ e $B$, fibras nervosas das cestas peripurkinjeanas normais. Em $C, D, E, F e G$, desintegração das bainhas de mielina, sob a forma de goticulas, em casos de cardiopatia crônica chagásica. Em $C, F$ e $G$ observam-se vários histiócitos carregados de gotículas de lipidios. (Coloração pelo Sudan B; oc. $10 \times$ obj. $45 \times$, Leitz). 


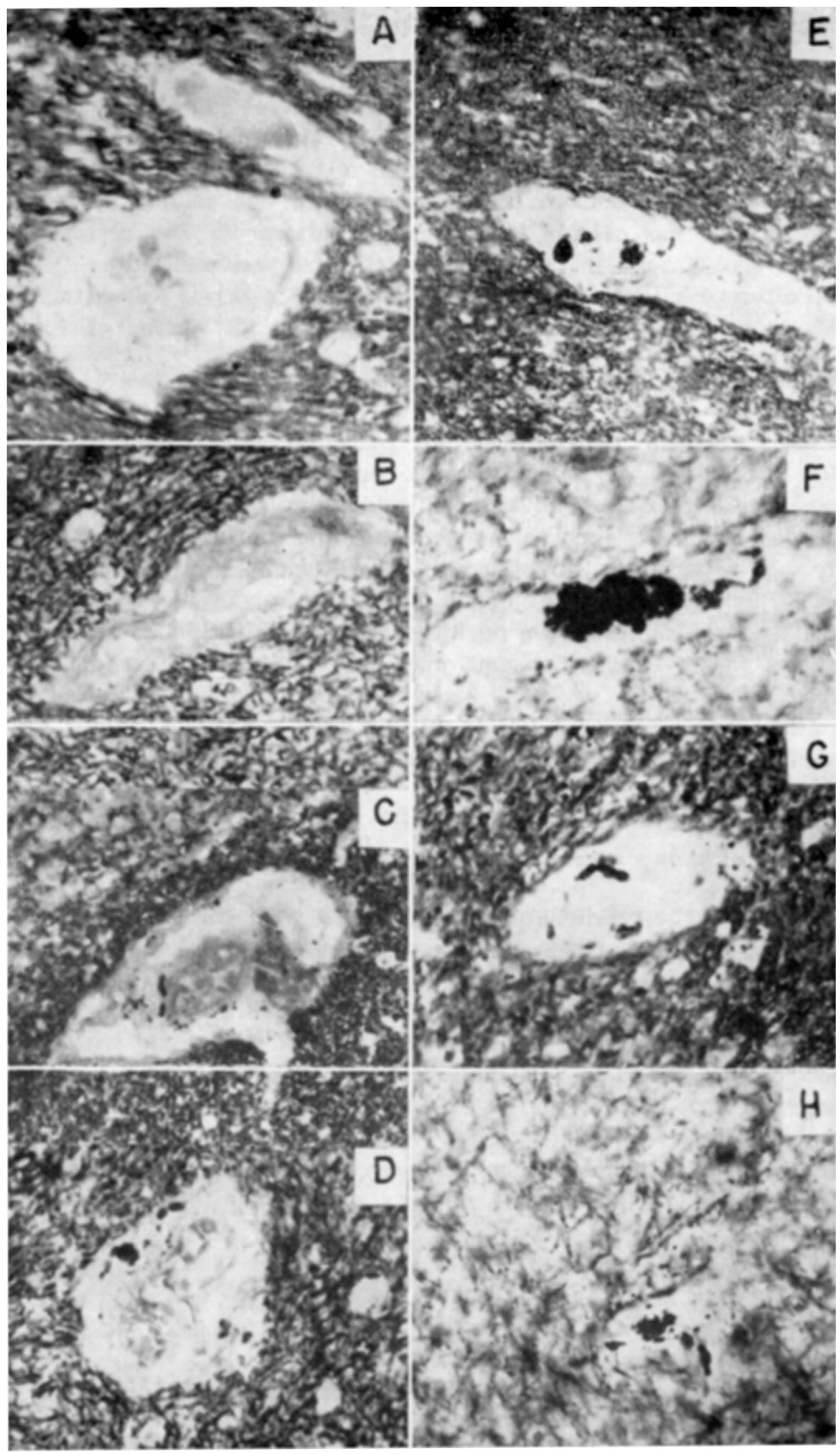

Fig. 5 - Em A e B, vasos sangüineos de cerebelo normal. Nas fotomicrografias seguintes, vasos sangüineos em casos de cardiopatia crônica chagásica, notando-se concentração de histiócitos, carregados de goticulas de lipidios, nos espaços perivasculares. (Coloração pelo Sudan B; oc. $10 \times-$ obj. $24 \times$, Leitz). 
Em conclusão, cabe dizer que no córtex cerebelar de pacientes com cardiopatias chagásicas crônicas encontram-se alterações microscópicas semelhantes às que já foram descritas em relação ao córtex cerebral 1, 2,3. Estas alterações consistem em redução numérica das células de Purkinje ", lesōes regressivas nas células remanescentes, alteraçōes das cestas peripurkinjeanas e mobilização histiocitária nos espaços perivasculares.

Tais alterações, entretanto, não são especificas da cardiopatia crônica chagásica, encontrando-se também em cardiopatias de outras etiologias.

\section{RESUMO}

Foram estudados 12 cerebelos de pacientes com cardiopatia crônica chagásica, 9 cerebelos de pacientes com cardiopatias não chagásicas (ambos os grupos constituidos de indivíduos falecidos em fase de insuficiência cardíaca congestiva) e dois cerebelos de indivíduos normais, falecidos acidentalmente. Nos pacientes chagásicos foi verificada redução numérica nas células de Purkinje, alterações de natureza regressiva nas células remanescentes, alterações das cestas peripurkinjeanas e mobilização microglial. Estas modificações foram também encontradas nos cerebelos dos cardiopatas não chagåsicos.

As alterações observadas foram interpretadas como resultantes da hipoxemia do sistema nervoso central devido à falência cardíaca.

\section{SUMMARY}

\section{Cerebellar changes in patients with chronic chagasic cardiopathy}

The study of the cerebellums of 12 patients with chronic Chagas' disease (chronic chagasic cardiopathy) has shown numeric reduction of the Purkinje cells with regressive changes in the remaining ones, changes in the nervous fibers of the Purkinje's cells nests and microgial mobilization. The same alterations were found in the cerebellums of 9 patients with non chagasic cardiopathy but, like the chagasic ones, with congestive heart failure. Two cerebelleums of "normal" persons accidentally died were used as controls.

The changes in the cerebellar parenchyma were considered as resulting from hypoxaemia of the central nervous system due to congestive heart failure.

\section{REFERENCIAS}

1. ALENCAR, A. - Atrofía do cérebro e anóxia na cardiopatia da doença de Chagas. An. Acad. brasil. Cien. 36:193-197, 1964.

2. ALENCAR, A. - Atrofia cortical na cardiopatia crônica chagásica. O Hospital (Rio de Janeiro) 66:807-815, 1964.

3. AlENCAR, A. - Atrofia cortical na cardiopatia crônica chagásica. An. Acad. brasil. Cienc. 1966, em publicação.

4. BRANDÃ, H. - Estudo do cerebelo em chagásicos. Apresentado ao V Congresso Brasileiro de Patologia, Nova Friburgo (Rio de Janeiro) 12 a 18 de julho, 1964.

Rua Machado de Assis 12, apt. 501 - Rio de Janeiro, GB - Brasil. 